\title{
Tobacco use pattern and quitting behaviour among healthcare professionals during the COVID-19 pandemic: Insights from a pan India online survey
}

\author{
Bijaya Nanda Naik, Bijit Biswas ", Chandramani Singh, Sanjay Pandey, Santosh Kumar Nirala, \\ Neha Chaudhary
}

Department of Community and Family Medicine, All India Institute of Medical Sciences, Patna, Bihar, India

\section{A R T I C L E I N F O}

\section{Keywords:}

COVID-19

Health personnel

Tobacco use

Tobacco use disorder

Tobacco use cessation

\begin{abstract}
A B S T R A C T
Background: Healthcare professionals (HCPs) have a definite role in tobacco control and can help immensely by setting examples. The current study aimed to study the tobacco use pattern and quitting behaviour among HCPs of India during the COVID-19 pandemic.

Methods: We addressed the research objective using a cross-sectional, anonymous online survey using 'google form" among 687 HCPs of India during December 2020. Descriptive and inferential statistics were performed using SPSS.

Results: Overall, $32.6 \%$ of the HCPs were ever tobacco user while $23.4 \%$ and $16.9 \%$ were current and daily tobacco user. During the COVID-19 pandemic, $51.7 \%$ and $43.1 \%$ of HCPs cut down the frequency and amount of tobacco use respectively while for $24.1 \%$ COVID-19 pandemic exerted no effect on their tobacco use. Presence of vulnerable population at home [ adjusted odds ratio (AOR): 17.5 (95\% confidence interval (CI): 3.3-92.2)], ever tobacco quit attempt [AOR: 13.5 (95\% CI:2.7-67.7)] and history of COVID-19 disease [AOR: 5.1 (95\% CI:1.3-20.7)] significantly determined reduced tobacco use $(60.3 \%)$ during the pandemic. Similarly, reduced tobacco use during the pandemic [AOR: 4.8 (95\% CI:1.7-13.5)] and perception of both smoking and smokeless tobacco form to be harmful for COVID-19 [AOR: 4.8 (95\% CI:1.7-13.5)] were the independent correlates of tobacco quit attempt (50.0\%) during the pandemic.

Conclusion: Tobacco use was quite rampant among the HCPs with every fourth and sixth being a current and daily tobacco user respectively. During the COVID-19 pandemic three in every five HCPs surveyed reduced tobacco use while every second HCP made a quit attempt.
\end{abstract}

\section{Introduction}

Tobacco use is unwarranted as it is known to increase risk of various communicable (i.e., pneumonia, tuberculosis etc.) and noncommunicable diseases (i.e., asthma, chronic obstructive pulmonary disease, lung cancer etc.). ${ }^{1-3}$ There is lack of evidence which can establish tobacco as risk factor for corona virus disease-19 (COVID-19). ${ }^{4,5}$ Although various researches labelled tobacco as cause of higher disease severity in hospitalized COVID-19 patients. ${ }^{6,7}$ World Health Organization (WHO) and various other organizations has discouraged tobacco use from very onset of the COVID-19 pandemic despite lack of concrete evidence suggesting its causal role. ${ }^{4,5}$ This caution on tobacco use might have been issued based on prevailing knowledge on tobacco as risk factor for various infectious respiratory illnesses. ${ }^{1,3,8}$
Being one of the largely affected countries in the COVID-19 pandemic, acceleration of tobacco control measures in India is need of the hour. ${ }^{9}$ In India tobacco use is quite rampant with every fourth adult person in the country (28.6\%) reported to be using it. The perception of harmful effects of tobacco is also considerably low as only $35.1 \%$ smokeless tobacco users and $49.3 \%$ tobacco users thought to be harmful in a recent pan India survey. ${ }^{10}$ Higher tobacco use prevalence (higher vulnerability), indiscriminate spitting of tobacco juice by smokeless tobacco users (can be a mode of COVID-19 spread) and lower risk perception (lower tobacco quitting behaviour) are prevailing major challenges of both tobacco and COVID-19 control in the country. ${ }^{11-13}$

The role of healthcare professionals (HCPs) (doctors and nurses) in tobacco control is indisputable. They can actively advice and counsel their patients for tobacco cessation. Moreover, by their own behaviour related to tobacco (i.e., quitting, discouragement etc.) they can influence

\footnotetext{
* Corresponding author. Department of Community and Family Medicine, All India Institute of Medical Sciences, Phulwarisharif, Patna, 801507, Bihar, India.

E-mail address: drbijitbiswas@gmail.com (B. Biswas).
} 
the concerned behaviour of many. But different prior surveys conducted in different parts of the world suggests that higher proportion of HCPs $(14.8-57.6 \%)$ are tobacco users themselves. ${ }^{14-18}$ A systematic review and metanalysis estimated $21.0 \%$ pooled prevalence of tobacco use among HCPs. ${ }^{19}$ Moreover, what is more concerning that HCPs who are tobacco users themselves less likely elicit tobacco related behaviour and advice for tobacco cessation among their patients. ${ }^{20,21}$ Thus, detailed exploration of tobacco related behaviours and their attributes of HCPs is need of the hour.

Despite our exhaustive efforts we could only retrieve few studies which explored tobacco related behaviour among HCPs of India. The prevailing Indian studies reported that tobacco consumption among healthcare workers may be as low as $<1 \%$ or it may be as high as $43.4 \% .{ }^{22-24}$ Moreover all these prior Indian studies requited study subjects from limited geographical area. There was no prior national survey which have explored the issue. Concerning effect of COVID-19 on tobacco related behaviour, there were few studies which explored the same among general population. ${ }^{25-28}$ Although, there was no published literature available globally or in India among HCPs regarding this. Therefore, this anonymous online survey was designed to elicit tobacco use pattern and quitting behaviour of HCPs (doctors and nurses) of India during the COVID-19 pandemic. The findings of the study will help us get a measure of the magnitude of the problem. Moreover, it will also help in identification of barriers and enablers of tobacco quitting behaviour among HCPs amid global pandemic.

\section{Methodology}

We addressed the research objective using an explorative crosssectional design. The online survey tool was self-administered to the potential study participants using 'google form' (an online selfadministered data collection tool by 'Google LLC') during December 2020. We included all HCPs (doctors and nurses) irrespective of their working sector (public/private), but they must possess a recognised degree in either modern or traditional medicine. A systematic review and meta-analysis by Nilan et al. ${ }^{19}$ reported $21 \%$ pooled prevalence of tobacco use among HCPs. Assuming the prevalence of tobacco use among HCPs of India to be $21 \%$, the minimum sample size for the study was calculated to be 643 using 'statulator' (an online sample size calculator) with $15 \%$ relative precision and $95 \%$ confidence level. A total of 687 HCPs during the study period consented to participate for the study.

A pre-tested structured questionnaire was used for the study and selfadministered as "google form". The questionnaire contained 6 sections. Section 1: Study description and digital informed consent. Section 2: (background characteristics) Age, sex, occupation, present residing state or union territory, educational stream, marital status, vulnerable population at home, ever came in unprotected contact of a COVID-19 suspect or case, ever being diagnosed with COVID-19. Section 3: [Mark the responses which describes your tobacco use status till date (ever/current/daily/never) (multiple response)] (For each tobacco use status working definitions as defined in the study protocol were enlisted against that particular response). Those who reported to be daily tobacco user were administered rest portions of the questionnaire. Section 4: (Tobacco use characteristics): Tobacco products used, preference of tobacco use (alone/with friends), effect of COVID-19 on tobacco use, preferred tobacco form (smoking/smokeless). As per preferred tobacco form the study participants were administered specific versions of Fagerstrom Nicotine Dependence Scale (FNDS) in section 5A (for smokers) ${ }^{29}$ and section $5 \mathrm{~B}$ (for smokeless tobacco users). ${ }^{30}$ Section 6 : (Perceived risk in COVID-19 and related practices): Perceived risk of tobacco use in COVID-19 disease causation and severity, perceived form of tobacco that increases risk of COVID-19, ever tried to quit tobacco, tried to quit tobacco during the COVID-19 pandemic, ever advised tobacco cessation to patients and family members. The study questionnaire was developed after consulting various experts of the field.
Followed by pretesting among 30 HCPs who were not included in the final sample. After required modifications based on received responses the tool was cleared for the final survey. FNDS for smokers had shown good internal consistency (Cronbach's alpha: 0.795) whereas FNDS for smokeless tobacco users was found to have acceptable internal consistency (Cronbach's alpha: 0.682).

The sampling technique used for the study was snow-ball type (nonprobabilistic sampling) as we forwarded the study google form link using various social media platforms (i.e., WhatsApp, Facebook and Linked In) to some HCPs and asked them to percolate it further. For identification of duplicate responses email id of each respondent were also documented in the study tool. If a respondent had submitted multiple responses only the last response was considered for analysis. Notably, no duplicate submission was found during analysis.

\subsection{Statistical analysis}

The information collected in the google forms was downloaded in Microsoft excel sheet and analysed using Statistical Package for Social Sciences (SPSS) (Version 22). Qualitative variables were reported using frequency (percentage) whereas mean [standard deviation (SD)] was used to report quantitative variables. Univariate logistic regression and multivariable logistic regression were performed to identify significant attributes of reduced tobacco use and quit attempt among HCPs during the pandemic. Odds ratio (OR) with $95 \%$ Confidence Interval (CI) were used to report the strength of association. For all analysis statistical significance was set at $\mathrm{p}$ value $<0.05$.

\subsection{Definitions used}

Reduced tobacco use: Those who reported to have cut down frequency and/or amount of tobacco consumption during the COVID-19 pandemic.

Ever tobacco user: Ever used tobacco till date (even a single stick or pouch). ${ }^{31}$

Current tobacco user: Used tobacco products in last 1 month (from the day of documenting response in the 'google form') (even a single stick or pouch). ${ }^{31}$

Daily tobacco user: Using tobacco products daily (on time of furnishing their response) (even a single stick or pouch). ${ }^{31}$

Nicotine dependence: Nicotine dependance score was calculated separately by summing up individual items of the respected scales for smokers and smokeless tobacco users. The minimum possible score for both the scales were 0 while maximum possible score for smokers and smokeless tobacco users' scales were 16 and 15 respectively. A nicotine dependance score of less than 5 was deemed as low to moderate dependance while a score of more than equal to 5 was deemed as moderate to high dependance for both smokers and smokeless tobacco users (Table 1). ${ }^{29,30}$

\section{Results}

\subsection{Study participants as per their present residing state and tobacco use} status

The participation of HCPs from various states of India is presented in Fig. 1. Maximum participants were from Bihar (36.5\%) followed by West Bengal (7.6\%), Delhi (7.1\%) and Uttar Pradesh (6.0\%). Overall, $32.6 \%$ of the HCPs were ever tobacco user while $23.4 \%$ and $16.9 \%$ were current and daily tobacco user respectively. Considering magnitude of daily tobacco use for each individual state for which at least 5 responses were available, West Bengal (23.1\%) topped the list followed by Punjab (20.0\%), Bihar (19.9\%), Haryana (18.2\%), Maharashtra (18.2\%) and Rajasthan (17.9\%) (Fig. 2). 
Table 1

Distribution of the study participants as per their responses of Fagerstrom nicotine dependence scale: $\mathrm{n}=116$.

\begin{tabular}{|c|c|c|}
\hline Variables & $\mathrm{N}(\%)$ & Score \\
\hline \multicolumn{3}{|l|}{ For Smokers: $(\mathrm{N}=91)$} \\
\hline \multicolumn{3}{|c|}{ How soon after waking do you smoke your first cigarette? } \\
\hline Within 5 min & 19 (20.9) & 3 \\
\hline $5-30 \mathrm{~min}$ & $22(24.2)$ & 2 \\
\hline $31-60 \mathrm{~min}$ & $50(54.9)$ & 1 \\
\hline \multicolumn{3}{|c|}{ Do you find it difficult to refrain from smoking in places where it is forbidden? } \\
\hline Yes & $37(40.7)$ & 1 \\
\hline No & $54(59.3)$ & 0 \\
\hline \multicolumn{3}{|c|}{ Which cigarette would you hate to give up? } \\
\hline The first one in the morning & $32(35.2)$ & 1 \\
\hline All others & $59(64.8)$ & 0 \\
\hline \multicolumn{3}{|c|}{ How many cigarettes a day do you smoke? } \\
\hline 10 or less & 70 (76.9) & 0 \\
\hline $11-20$ & 15 (16.5) & 1 \\
\hline $21-30$ & $6(6.6)$ & 2 \\
\hline 31 or more & $0(0.0)$ & 3 \\
\hline \multicolumn{3}{|c|}{ Do you smoke more frequently in the morning? } \\
\hline Yes & $32(35.2)$ & 1 \\
\hline No & $59(64.8)$ & 0 \\
\hline \multicolumn{3}{|c|}{ Do you smoke even if you are sick? } \\
\hline Yes & 45 (49.5) & 1 \\
\hline No & $46(50.5)$ & 0 \\
\hline \multicolumn{3}{|c|}{ For smokeless tobacco users: $(\mathrm{N}=25)$} \\
\hline \multicolumn{3}{|c|}{ How soon after you wake up, you consume your first smokeless tobacco pouch? } \\
\hline Within $5 \mathrm{~min}$ & $4(16.0)$ & 3 \\
\hline $6-30 \mathrm{~min}$ & $5(20.0)$ & 2 \\
\hline $31-60 \mathrm{~min}$ & $6(24.0)$ & 1 \\
\hline After $60 \mathrm{~min}$ & $10(40.0)$ & 0 \\
\hline \multicolumn{3}{|c|}{ How often do you intentionally swallow tobacco juice? } \\
\hline Always & $6(24.0)$ & 2 \\
\hline Sometimes & $14(56.0)$ & 1 \\
\hline Never & $5(20.0)$ & 0 \\
\hline \multicolumn{3}{|c|}{ Which smokeless tobacco intake is most difficult for you to quit? } \\
\hline The first one in the morning & $11(44.0)$ & 1 \\
\hline All others & $14(56.0)$ & 0 \\
\hline \multicolumn{3}{|c|}{ How many cans/pouches per week do you use? } \\
\hline More than 3 & $7(28.0)$ & 2 \\
\hline $2-3$ & $10(40.0)$ & 1 \\
\hline 1 & $8(32.0)$ & 0 \\
\hline \multicolumn{3}{|c|}{ Do you chew more frequently during the first hours after awakening than during the rest of the day? } \\
\hline Yes & $15(60.0)$ & 1 \\
\hline No & $10(40.0)$ & 0 \\
\hline \multicolumn{3}{|c|}{ Do you chew even if you are ill? } \\
\hline Yes & $19(76.0)$ & 1 \\
\hline No & $6(24.0)$ & 0 \\
\hline
\end{tabular}

\subsection{Background characteristics of the study participants}

The mean age of the daily tobacco users were 32.5 years with standard deviation (SD) of 8.9 years. Majority of them were male $(91.4 \%)$, doctor (89.7\%) and practicing modern medicine (97.1\%). About half of them $(48.2 \%)$ were currently married while $21.4 \%$ of them were not staying with their spouse. Most of the HCPs (60.3\%) had vulnerable population at home (Table 2).

\subsection{Tobacco use behaviour of the daily tobacco users}

Majority of the daily tobacco users preferred smoking form of tobacco $(78.4 \%)$ and had preference for cigarettes $(81.0 \%)$ followed by Gutka (a form of smokeless tobacco) (19.0\%) and Zarda (a form of smokeless tobacco) (6.9\%). A quarter $(25.0 \%)$ of the participants were found to have moderate to severe dependence on nicotine and the rest $(75.0 \%)$ have low to moderate dependence on nicotine (Table 3 ).

\subsection{Effect of COVID-19 on tobacco use}

Overall, three-fifth $(60.3 \%)$ of the HCPs have either cut down tobacco use frequency or amount. About half of the study subjects (51.7\%) have cut down frequency of tobacco use while $43.1 \%$ have cut down amount of tobacco use. Three-fourth (27.6\%) of the HCPs have stopped consuming with peers while for $24.1 \%$ the pandemic did not make any impact on their tobacco use (Fig. 3).

\subsection{Determinants of reduced tobacco use and quit attempt during the pandemic}

In multivariable logistic regression model; presence of vulnerable population at home [ adjusted odds ratio (AOR): 17.5 (3.3-92.2)], ever tobacco quit attempt [AOR: 13.5 (2.7-67.7)] and history of COVID-19 disease [AOR: $5.1(1.3-20.7)]$ significantly determined reduced tobacco use among the HCPs during the pandemic $\left[\mathrm{R}^{2}=62.2 \%\right.$; predictive accuracy rate $(\mathrm{PAR})=84.5 \%]$. Reduced tobacco use during the pandemic [AOR: 4.8 (1.7-13.5)] and perception of both smoking and smokeless tobacco form to be harmful for COVID-19 [AOR: 4.8 (1.7-13.5)] were the multivariable associates of tobacco quit attempt during the pandemic $\left[\mathrm{R}^{2}=35.8 \%\right.$; predictive accuracy rate (PAR) $=$ 73.3\%] (Table 4).

\section{Discussion}

We administered a self-administered structured questionnaire in online mode using cross-sectional design among HCPs of India to elicit 
$>50$

$41-50$

$31-40$

21-30

$11-20$

$\leq 10$

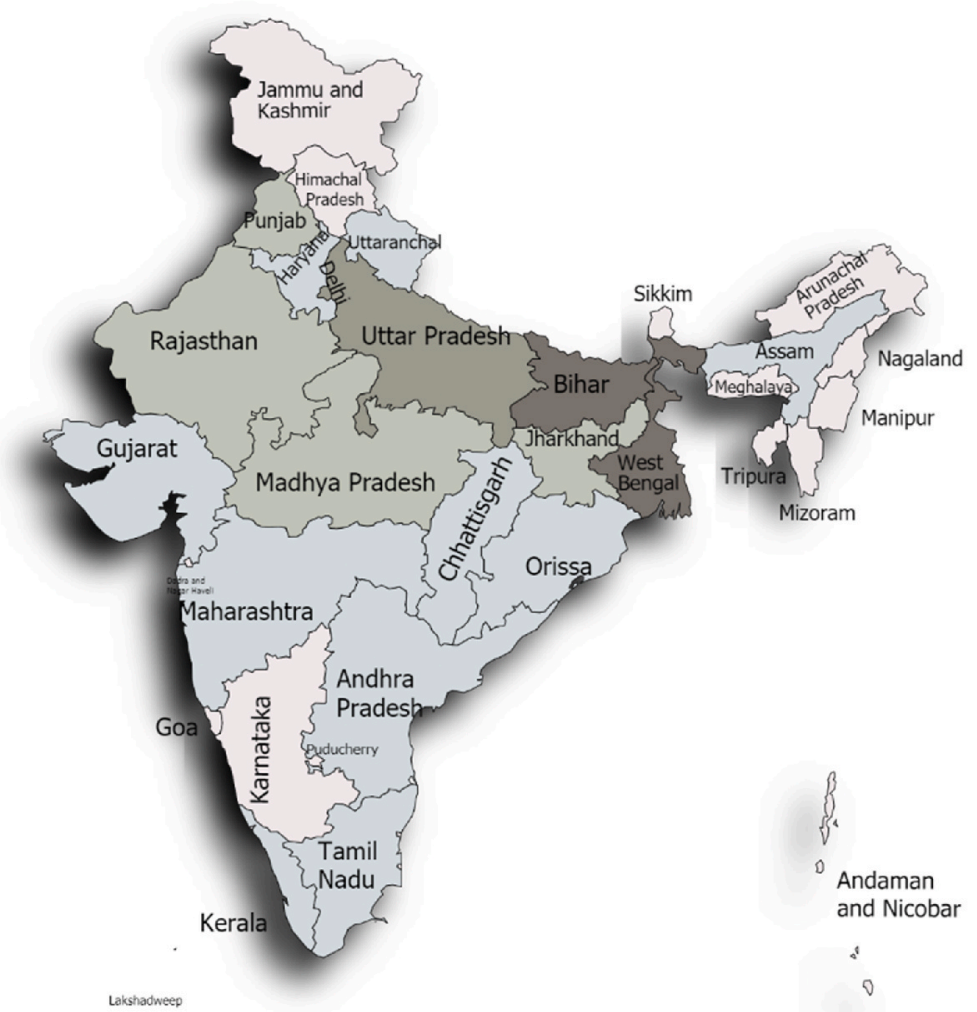

Created with paintmaps.com

Fig. 1. Map of India showing distribution of the study subjects as per their present residing state or union territory.

$21-25 \%$

$16-20 \%$

$11-15 \%$

6-10\%

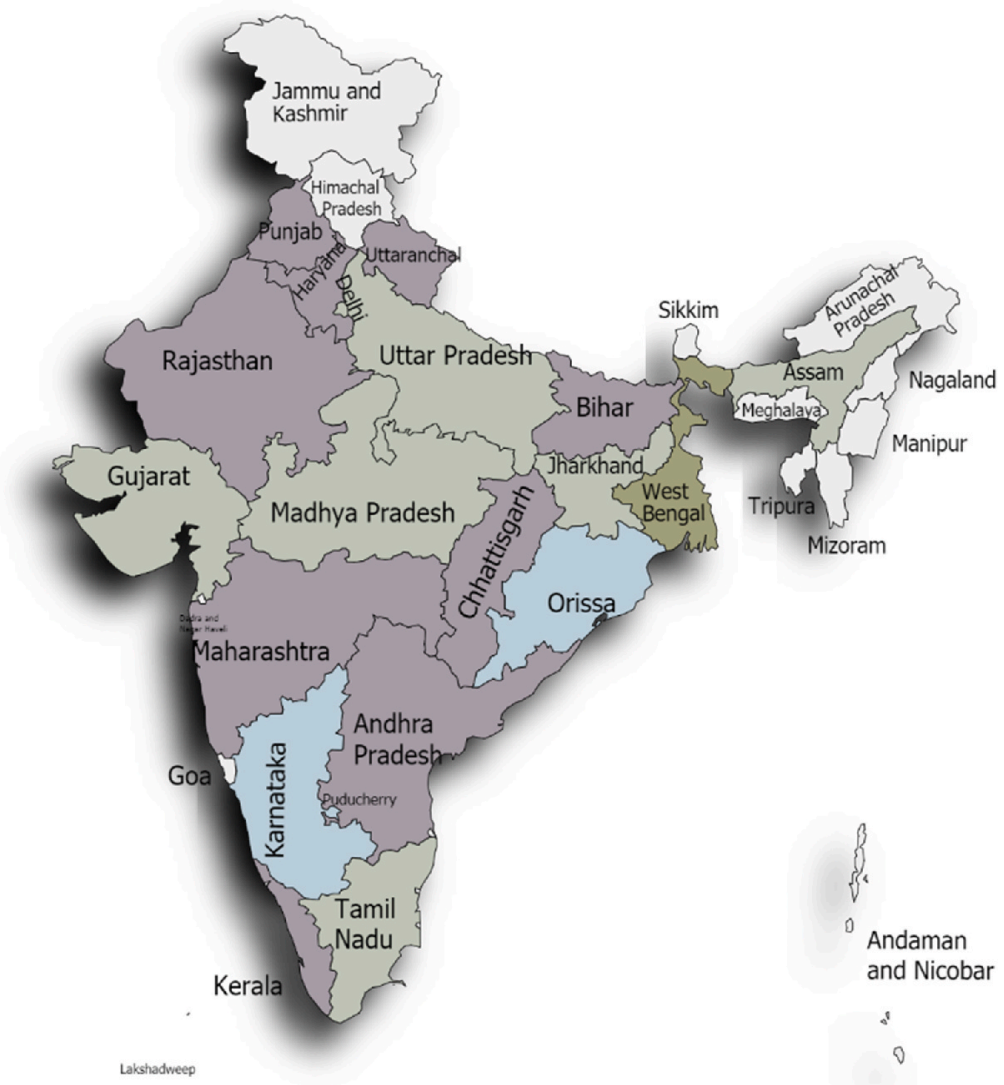

Fig. 2. Map of India showing distribution of the proportion of the study subjects using tobacco products daily as per their present residing state or union territory. 
Table 2

Background characteristics of the study participants: $n=116$.

\begin{tabular}{|c|c|}
\hline Variable & N (\%) \\
\hline \multicolumn{2}{|l|}{ Age in completed years: } \\
\hline$<30$ & $56(48.3)$ \\
\hline $30-39$ & $38(32.8)$ \\
\hline $40-49$ & $15(12.9)$ \\
\hline$\geq 50$ & $7(6.0)$ \\
\hline \multicolumn{2}{|l|}{ Gender: } \\
\hline Male & $106(91.4)$ \\
\hline Female & $10(8.6)$ \\
\hline \multicolumn{2}{|l|}{ Occupation: } \\
\hline Doctor & $104(89.7)$ \\
\hline Nurse & $12(10.3)$ \\
\hline \multicolumn{2}{|l|}{ Educational Stream: } \\
\hline Modern medicine & $101(87.1)$ \\
\hline Nursing & $12(10.3)$ \\
\hline Dental & $1(0.9)$ \\
\hline AYUSH* & $2(1.7)$ \\
\hline \multicolumn{2}{|l|}{ Marital Status: } \\
\hline Currently married and staying with spouse & $44(37.9)$ \\
\hline Currently married but not staying with spouse & $12(10.3)$ \\
\hline Currently unmarried & $58(50.0)$ \\
\hline Divorced/Separated & $2(1.7)$ \\
\hline \multicolumn{2}{|c|}{ Vulnerable population at home: (multiple response) } \\
\hline Children aged $<10$ years & $43(37.1)$ \\
\hline Elderly aged $\geq 60$ years & $42(36.2)$ \\
\hline Persons with chronic disease (i.e., $\mathrm{HTN}^{\dagger}, \mathrm{DM}^{\ddagger}$ ) & $40(34.5)$ \\
\hline Not Applicable & $46(39.7)$ \\
\hline
\end{tabular}

*Ayurveda, Yoga \& Naturopathy, Unani, Siddha and Homoeopathy.

†hypertension.

${ }^{\ddagger}$ diabetes mellitus.

Table 3

Practices and perceptions related to tobacco use in context of COVID-19 among the study participants: $\mathrm{n}=116$.

\begin{tabular}{|c|c|}
\hline Variable & N (\%) \\
\hline \multicolumn{2}{|l|}{ Type of tobacco products consumed: } \\
\hline Cigarette & $94(81.0)$ \\
\hline Bidi & $5(4.3)$ \\
\hline Gutka & $22(19.0)$ \\
\hline Khaini & $7(6.0)$ \\
\hline Zarda & $8(6.9)$ \\
\hline Others & $2(1.7)$ \\
\hline \multicolumn{2}{|l|}{ Preferred tobacco form: } \\
\hline Smoking & $91(78.4)$ \\
\hline Smokeless & $25(21.6)$ \\
\hline \multicolumn{2}{|l|}{ Nicotine Dependence: } \\
\hline Low to moderate & $87(75.0)$ \\
\hline Moderate to high & $29(25.0)$ \\
\hline \multicolumn{2}{|l|}{ Preference of tobacco use: } \\
\hline With friends or colleagues & $42(36.2)$ \\
\hline Alone & $74(63.8)$ \\
\hline Ever tried to quit tobacco: (Yes) & $83(71.6)$ \\
\hline Made tobacco quit attempt during the COVID*-19 pandemic: (Yes) & $58(50.0)$ \\
\hline Perceived tobacco as risk factor for COVID*-19 disease causation: (Yes) & $58(50.0)$ \\
\hline Perceived tobacco as risk factor for COVID*-19 disease severity: (Yes) & $80(69.0)$ \\
\hline \multicolumn{2}{|l|}{ Perceived tobacco form that increases the risk of COVID*-19: } \\
\hline Only smoking & $61(52.6)$ \\
\hline Only Smokeless tobacco & $9(7.8)$ \\
\hline Both smoking and smokeless tobacco & $31(26.7)$ \\
\hline None & $15(12.9)$ \\
\hline Ever came in unprotected contact with a suspect or confirmed COVID-19 case: (Yes) & $60(51.7)$ \\
\hline Ever diagnosed with COVID-19: (Yes) & $42(36.2)$ \\
\hline
\end{tabular}

*Corona Virus Disease. 


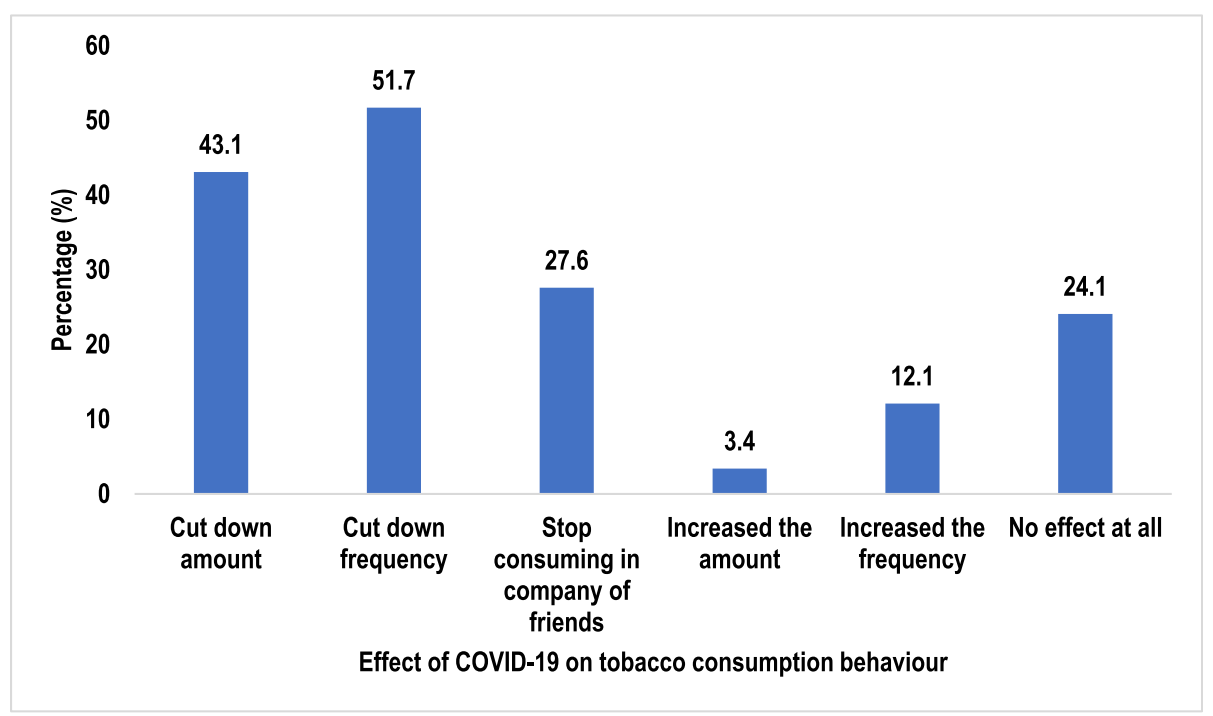

Fig. 3. Bar chart showing distribution of the study subjects as per effect of COVID-19 pandemic on their tobacco consumption behaviour: (multiple response).

Table 4

Univariate and multivariable logistic regression analysis showing predictors of reduced tobacco use and quit attempt during the COVID-19 pandemic among the healthcare professionals: $\mathrm{n}=116$.

\begin{tabular}{|c|c|c|c|c|c|c|}
\hline \multirow{2}{*}{ Variable } & \multicolumn{3}{|c|}{ Reduced tobacco Use; Yes $=70(60.3 \%)$} & \multicolumn{3}{|c|}{ Made tobacco quit attempt; Yes $=58(50.0 \%)$} \\
\hline & $\mathrm{N}(\%)$ & $\mathrm{COR}^{\dagger}\left(95 \% \mathrm{CI}^{\ddagger}\right)$ & $\operatorname{AOR}^{\S}\left(95 \% \mathrm{CI}^{\ddagger}\right)$ & $\mathrm{N}(\%)$ & $\mathrm{COR}^{\dagger}\left(95 \% \mathrm{CI}^{\ddagger}\right)$ & $\mathrm{AOR}^{\S}\left(95 \% \mathrm{CI}^{\ddagger}\right)$ \\
\hline Age in years: $(<30)$ & $40(71.4)$ & $2.5(1.2-5.4)$ & $3.4(0.8-14.1)$ & $27(48.2)$ & $0.9(0.4-1.8)$ & - \\
\hline Gender: (Female) & $9(90.0)$ & $6.6(0.8-54.3)$ & - & $3(30.0)$ & $0.4(0.1-1.6)$ & - \\
\hline Occupation: (Doctor) & $63(60.6)$ & $1.1(0.3-3.7)$ & - & $53(51.0)$ & $1.4(0.4-4.9)$ & - \\
\hline \multicolumn{7}{|l|}{ Marital Status: } \\
\hline Married and staying with partner & $23(52.3)$ & $0.4(0.2-0.9)$ & $0.2(0.0-1.3)$ & $23(52.3)$ & $1.2(0.6-2.7)$ & - \\
\hline Married and not staying with partner & $4(33.3)$ & $0.2(0.1-0.7)$ & $0.4(0.1-2.8)$ & $7(58.3)$ & $1.6(0.5-5.6)$ & - \\
\hline Unmarried/divorced/separated & $43(71.7)$ & Ref. & Ref. & $28(46.7)$ & Ref. & \\
\hline Vulnerable population at home: (Yes) & $50(71.4)$ & $3.3(1.5-7.1)$ & $17.5(3.3-92.2)$ & $41(58.6)$ & $2.4(1.1-5.2)$ & $1.0(0.4-2.8)$ \\
\hline \multicolumn{7}{|l|}{ Preferred tobacco form: } \\
\hline Smokeless & $16(64.0)$ & $1.2(0.5-3.0)$ & - & $18(72.0)$ & $3.3(1.2-8.6)$ & $2.9(0.9-8.9)$ \\
\hline Smoking & $54(59.3)$ & Ref. & & $40(44.0)$ & Ref. & Ref. \\
\hline \multicolumn{7}{|l|}{ Preference of tobacco use: } \\
\hline With friends or colleagues & $28(66.7)$ & $1.5(0.7-3.3)$ & - & $23(54.8)$ & $1.3(0.6-2.9)$ & - \\
\hline Alone & $42(56.8)$ & Ref. & & $35(47.3)$ & Ref. & \\
\hline \multicolumn{7}{|l|}{ Nicotine dependence: } \\
\hline Low to moderate & $59(67.8)$ & $3.4(1.4-8.3)$ & $3.4(0.9-12.2)$ & $49(56.3)$ & $2.9(1.2-7.0)$ & $3.0(0.9-9.5)$ \\
\hline Moderate to high & $11(37.9)$ & Ref. & Ref. & $9(31.0)$ & Ref. & Ref. \\
\hline Ever tried to quit tobacco: (Yes) & $62(74.7)$ & $9.2(3.6-23.5)$ & $13.5(2.7-67.7)$ & - & - & - \\
\hline Reduced tobacco use during the COVID*-19 pandemic: (Yes) & - & - & - & $46(65.7)$ & $5.4(2.4-12.4)$ & $4.8(1.7-13.5)$ \\
\hline Perceived tobacco as risk factor for COVID*-19 disease causation: (Yes) & $45(77.6)$ & $4.6(2.0-10.2)$ & $3.1(0.8-12.5)$ & $34(56.8)$ & $2.0(0.9-4.2)$ & - \\
\hline Perceived tobacco as risk factor for COVID*-19 disease severity: (Yes) & $53(66.3)$ & $2.2(0.9-4.9)$ & - & $37(46.3)$ & $0.6(0.3-1.4)$ & - \\
\hline \multicolumn{7}{|l|}{ Perceived tobacco form that increases the risk of COVID*-19: } \\
\hline Smoking & $44(72.1)$ & $6.3(2.2-17.8)$ & $3.2(0.7-14.2)$ & $30(49.2)$ & $2.9(1.0-8.3)$ & $1.7(0.5-5.7)$ \\
\hline Both smoking and smokeless & $19(61.3)$ & $3.8(1.2-12.0)$ & $0.3(0.1-2.1)$ & $22(71.0)$ & $7.3(2.2-24.5)$ & $7.3(1.8-30.3)$ \\
\hline Others & $7(29.2)$ & Ref. & Ref. & $6(25.0)$ & Ref. & Ref. \\
\hline History of unprotected contact with COVID*-19 case or suspect: (Yes) & $39(65.0)$ & $1.5(0.7-3.2)$ & - & $32(53.3)$ & $1.3(0.6-2.7)$ & - \\
\hline History of ever diagnosed with COVID*-19: (Yes) & $34(81.0)$ & $4.5(1.8-10.9)$ & $5.1(1.3-20.7)$ & $26(61.9)$ & $2.1(0.9-4.6)$ & - \\
\hline Negelkerke $\mathrm{R}^{2}$ : & - & - & .622 & - & - & .358 \\
\hline Hosmer Lemeshow test p-value: & - & - & 0.07 & - & - & 0.33 \\
\hline Predictive accuracy rate (PAR): & - & - & 84.5 & - & - & 73.3 \\
\hline
\end{tabular}

*Corona Virus Disease.

${ }^{\dagger}$ crude odds ratio.

${ }^{\ddagger}$ confidence interval.

§adjusted odds ratio.

their tobacco use pattern and quitting behaviour during the COVID-19 pandemic. We found that every fourth and sixth study participant was a current and daily tobacco user respectively. Among daily tobacco users, every fourth HCP had moderate to high nicotine dependence. During the pandemic three in every five-study participant surveyed reduced tobacco use while every second HCP made a quit attempt.

\subsection{Prevalence and pattern of tobacco use}

Overall, we found that $32.6 \%$ of the study participants were ever tobacco user while $23.4 \%$ and $16.9 \%$ were current and daily tobacco user. Compared to our findings, less proportion of HCPs were reported to be tobacco users by Mony et al. ${ }^{22}$ (reported $6.9 \%, 2 \%$ and $<1 \%$ tobacco use among physicians, line workers and nurses respectively) and Sharma 
et al. $^{24}$ (reported $12.5 \%$ healthcare workers as current tobacco users) whereas higher proportion by Prasad et al. ${ }^{23}$ (reported $43.4 \%$ healthcare workers as current tobacco users). Smoking (78.4\%) was the most preferred form of tobacco use among HCPs in our study. Similar observations have been made by Sharma et al. ${ }^{24}$ but predominant smokeless tobacco use among healthcare workers have been reported by Prasad et al. ${ }^{23}$ The variability of the findings may be due to use of selected geographical area for recruitment of the study participants ${ }^{22-24}$ unlike ours which had participation from all corners of the country. Moreover, Mony et al. ${ }^{22}$ and Prasad et al. ${ }^{23}$ had recruited support staff (i. e. line workers, housekeeping staff etc.) in their sample in addition to HCPs which was unlike us.

\subsection{Impact of COVID-19 pandemic on tobacco use}

A high proportion $(60.3 \%)$ of HCPs who were using tobacco have reduced tobacco use $(60.3 \%$; $51.7 \%$ reduced frequency and $43.1 \%$ cut down amount) and have made quit attempt (50.0\%) during the pandemic in the present study. Despite extensive review we couldn't come across studies which have reported change in tobacco use behaviour among HCPs during the pandemic. However, few studies have explored the tobacco use behaviour during the pandemic among tobacco users in general population. Reduction in tobacco use among tobacco users in general population was less compared to our study [Chertok. ${ }^{20}: 38.3 \%$ decreased smoking and $21.3 \%$ decreased frequency; Streck et al. ${ }^{21}: 21.0 \%$ reported smoking less; Yingst et al. ${ }^{22}: 15 \%$ reported decrease in their tobacco use).]. Similarly, tobacco quit attempt was lower among the tobacco users in general population as reported by Chertok. ${ }^{20}(36.7 \%)$ and Yingst et al. ${ }^{22}(24.5 \%)$. The proportion of HCPs (24.1\%) in our study whose tobacco use did no change during the pandemic was very less compared to general population as reported by Chertok. ${ }^{20}$ (43.3\%), Streck et al. ${ }^{21}(44.0 \%)$ and Gupte et al. ${ }^{23}(70.0 \%)$. The HCPs are a special group and highly informed. Being well and adequately informed greatly influences the behaviour change. ${ }^{24}$ Thus percolation of adequate information on ill effects of tobacco in general population might bring about a greater change on their tobacco use behaviour. In this aspect HCPs might play a huge role by active counselling of their patients and refraining themselves from all tobacco products.

\subsection{Determinants of reduced tobacco use and quit attempt during the pandemic}

In the present study with increasing age odds of reduced tobacco use among the study subjects during the pandemic also increased. Although such relation did not hold true for quit attempt during the pandemic. A study from US also have made similar observations of increased quit attempts among older current tobacco users. ${ }^{20}$ This might be because of increased risk perception of both contracting and death due to COVID-19 among older individuals compared to younger ones. ${ }^{32}$ In our study HCPs who perceived tobacco as risk factor for COVID-19 were more likely to reduce tobacco use during the pandemic. Similarly, HCPs who perceived both smoking and smokeless tobacco to be harmful for COVID-19 were more likely to do both tobacco use reduction and quit attempt. A longitudinal study during lockdown from India ${ }^{23}$ reported similar observations where $51 \%$ of the tobacco users stopped tobacco use due to their concerns about coronavirus. Similarly a study from $\mathrm{US}^{25}$ reported perceived risk of severe COVID-19 infection among smokers as predictor of desire to quit smoking since COVID-19. In our study, HCPs previously diagnosed with COVID-19 were more likely to reduce tobacco use during the pandemic. This might be due to their fear of reinfection or having severe form of the disease. The other possible reason could be restricted or no access to tobacco products due to quarantine/hospitalisation as a result of COVID-19 illness. ${ }^{33}$ HCPs, who were married and staying with partner in the current study, were more likely to reduce tobacco use compared to those who were currently married and not staying with their partner. HCPs with vulnerable population at home were more likely to reduce tobacco use and make quit attempt during the pandemic. It was in line with the findings of Yingst et al. $^{22}$ were $31.6 \%$ study participants reported being around other non-smokers as the reason behind their reduced tobacco use. These findings are also in accordance with health belief model (HBM) which suggests that perceived risk for a disease significantly influences the behaviour associated with it. ${ }^{34}$

HCPs who had low to moderate nicotine dependence were more likely reduce tobacco use and make quit attempt during the pandemic than those with moderate to high nicotine dependence in the present study. High nicotine dependence needs higher mental determination, counselling and medical interventions to reduce or quit tobacco use. This could possibly explain the reason behind significant association between reduction in tobacco use and quit attempt in our study. In a cohort study from $\mathrm{US}^{35}$ reported that tobacco users who had high nicotine dependence were 4.7 points less likely to achieve cessation at any point. This was in line with our observations.

\subsection{Limitations}

As per our knowledge based on exhaustive literature search, this was the first study conducted among HCPs of India which has elucidated their tobacco use pattern and quit attempt during the COVID-19 pandemic. Due to adaptation of self-administered method for data collection, the reporting, professional and social desirability related biases could not have been eliminated completely and possibly would have influenced the findings. However, we expect the occurrence of the prementioned biases to be low as the survey was administered in a highly educated study population, and participants were ensured about their confidentiality and anonymity. Moreover, participation of HCPs from every part of the country ensured data diversity and made the findings of the study more robust.

\section{Conclusions}

Tobacco use was quite rampant among the HCPs with every fourth and sixth being a current and daily tobacco user respectively. Presence of vulnerable population at home, ever tobacco quit attempt and history of COVID-19 disease significantly determined reduced tobacco use during the pandemic. Similarly, reduced tobacco use during the pandemic and perception of both smoking and smokeless tobacco form to be harmful for COVID-19 were found to be independent correlates of tobacco quit attempt during the pandemic. Being role model of the tobacco cessation campaign effective enforcement of tobacco cessation drive among HCPs is warranted. Good sign is during the COVID-19 pandemic three in every five-study participant surveyed reduced tobacco use while every second HCP made a quit attempt. They should be mentally supported to achieve and sustain tobacco abstinence.

\section{Funding}

This research received no specific grant from any funding agency in the public, commercial, or not-for-profit sectors.

\section{Ethics approval}

Ethics approval was obtained from Institutional Ethics Committee (IEC) of AIIMS-Patna (AIIMS/Pat/IEC/2020/633). In addition, digital informed consent from each study participant was obtained.

\section{Declaration of competing interest}

The authors have no conflicts of interest associated with the material presented in this paper. 


\section{Acknowledgement}

We would like to thank all the healthcare professionals who enthusiastically participated and forwarded the study link to their peers, colleagues and contacts. Without their unconditional support this study would not have been possible.

\section{References}

1 Baskaran V, Murray RL, Hunter A, Lim WS, McKeever TM. Effect of tobacco smoking on the risk of developing community acquired pneumonia: a systematic review and meta-analysis. PloS One. 2019;14(7), e0220204. https://doi.org/10.1371/journal. pone.0220204.

2 American Cancer Society. Health risks of smoking tobacco. Accessed https://www. cancer.org/healthy/stay-away-from-tobacco/health-risks-of-tobacco/health-risksof-smoking-tobacco.html; 2020. Accessed January 31, 2021.

3 Jayes L, Haslam PL, Gratziou CG, et al. SmokeHaz: systematic reviews and metaanalyses of the effects of smoking on respiratory health. Chest. 2016;150(1):164-179. https://doi.org/10.1016/j.chest.2016.03.060.

4 Centers for Disease Control and Prevention (CDC). COVID-19 and your health. Published February 11, 2020. Accessed https://www.cdc.gov/coronavirus/2019-nc ov/need-extra-precautions/people-with-medical-conditions.html. Accessed February 14, 2021.

5 World Health Organization (WHO). Smoking and COVID-19. Published https://www .who.int/news-room/commentaries/detail/smoking-and-covid-19; 2020. Accessed October 20, 2020. Accessed.

6 Cattaruzza MS, Zagà V, Gallus S, D’Argenio P, Gorini G. Tobacco smoking and COVID-19 pandemic: old and new issues. A summary of the evidence from the scientific literature. Acta Biomed. 2020;91(2):106-112. https://doi.org/10.23750/ abm.v91i2.9698.

7 Gülsen A, Yigitbas BA, Uslu B, Drömann D, Kilinc O. The effect of smoking on COVID19 symptom severity: systematic review and meta-analysis. Pulm Med. 2020;2020: 7590207. https://doi.org/10.1155/2020/7590207.

8 Jiang C, Chen Q, Xie M. Smoking increases the risk of infectious diseases: a narrative review. Tob Induc Dis. 2020;18:60. https://doi.org/10.18332/tid/123845.

9 WHO coronavirus (COVID-19) dashboard. Accessed https://covid19.who.int; 2021. Accessed March 6, 2021.

10 Global Adult Tobacco Survey (GATS). Second round, India (2016-17). Accessed https ://ntcp.nhp.gov.in/assets/document/surveys-reports-publications/Global-AdultTobacco-Survey-Second-Round-India-2016-2017.pdf. Accessed October 20, 2020.

11 Ahluwalia IB, Myers M, Cohen JE. COVID-19 pandemic: an opportunity for tobacco use cessation. Lancet Public Health. 2020;5(11):e577. https://doi.org/10.1016/ S2468-2667(20)30236-X.

12 Kaur J, Rinkoo AV. Public health perspectives of smokeless tobacco and areca nut use in the COVID-19 era. Nicotine Tob Res. 2020;22(9):1660-1661. https://doi.org/ $10.1093 /$ ntr/ntaa081.

13 Sivapuram MS, Nagarathna R, Anand A, Patil S, Singh A, Nagendra HR. Prevalence of alcohol and tobacco use in India and implications for COVID-19 - niyantrita madhumeha bharata study projections. J Med Life. 2020;13(4):499-509. https://doi. org/10.25122/jml-2020-0079.

14 Bafunno D, Catino A, Lamorgese V, et al. Smoking prevalence, knowledge and perceptions on tobacco control among healthcare professionals: a survey in an Italian cancer center. J Community Health. 2021;46(3):597-602. https://doi.org/10.1007/ s10900-020-00907-8.

15 Mahdi HA, Elmorsy SA, Melebari LA, et al. Prevalence and intensity of smoking among healthcare workers and their attitude and behavior towards smoking cessation in the western region of Saudi Arabia: a Cross-sectional study. Tob Prev Cessation. 2018;4:30. https://doi.org/10.18332/tpc/93787.

16 Mahfouz AA, Shatoor AS, Al-Ghamdi BR, et al. Tobacco use among health care workers in southwestern Saudi arabia. BioMed Res Int. 2013;2013:960292. https:// doi.org/10.1155/2013/960292.
17 Malik M, Javed D, Hussain A, Essien EJ. Smoking habits and attitude toward smoking cessation interventions among healthcare professionals in Pakistan. J Fam Med Prim Care. 2019;8(1):166-170. https://doi.org/10.4103/jfmpc.jfmpc_230_18.

18 Zinonos S, Zachariadou T, Zannetos S, Panayiotou AG, Georgiou A. Smoking prevalence and associated risk factors among healthcare professionals in Nicosia general hospital, Cyprus: a cross-sectional study. Tob Induc Dis. 2016;14(1):14. https://doi.org/10.1186/s12971-016-0079-6.

19 Nilan K, McKeever TM, McNeill A, Raw M, Murray RL. Prevalence of tobacco use in healthcare workers: a systematic review and meta-analysis. PloS One. 2019;14(7), e0220168. https://doi.org/10.1371/journal.pone.0220168.

20 Abdulateef DS, Ali AJ, Abdulateef DS, Mohesh MIG. Smoking knowledge, attitude, and practices among health care professionals from sulaymaniyah city/Iraq. Tob Use Insights. 2016;9:1-6. https://doi.org/10.4137/TUI.S38171.

21 Mostafa N, Momen M. Effect of physicians' smoking status on their knowledge, attitude, opinions and practices of smoking cessation in a University Hospital, in Egypt. J Egypt Publ Health Assoc. 2017;92(2):96-106. https://doi.org/10.21608/ EPX.2018.8947.

22 Mony PK, Vishwanath NS, Krishnan S. Tobacco use, attitudes and cessation practices among healthcare workers of a city health department in Southern India. J Fam Med Prim Care. 2015;4(2):261-264. https://doi.org/10.4103/2249-4863.154670.

23 Prasad N, Singh M, Pal RK, Joseph J. Tobacco use among health care workers of tertiary care center of Faridabad, Haryana, India. Clinical Epidemiology and Global Health. 2020;8(2):394-398. https://doi.org/10.1016/j.cegh.2019.09.009.

24 Sharma S, Anand T, Kishore J, Dey BK, Ingle GK. Prevalence of modifiable and nonmodifiable risk factors and lifestyle disorders among health care professionals. Astrocyte. 2014;1(3):178-185. https://doi.org/10.4103/2349-0977.157757.

25 Chertok IRA. Perceived risk of infection and smoking behavior change during COVID-19 in Ohio. Publ Health Nurs. 2020;37(6):854-862. https://doi.org/10.1111/ phn. 12814.

26 Streck JM, Kalkhoran S, Bearnot B, et al. Perceived risk, attitudes, and behavior of cigarette smokers and nicotine vapers receiving buprenorphine treatment for opioid use disorder during the COVID-19 pandemic. Drug Alcohol Depend. 2021;218: 108438. https://doi.org/10.1016/j.drugalcdep.2020.108438.

27 Yingst JM, Krebs NM, Bordner CR, Hobkirk AL, Allen SI, Foulds J. Tobacco use changes and perceived health risks among current tobacco users during the COVID19 pandemic. Int J Environ Res Publ Health. 2021;18(4):1795. https://doi.org/ 10.3390/ijerph18041795.

28 Gupte HA, Mandal G, Jagiasi D. How has the COVID-19 pandemic affected tobacco users in India: lessons from an ongoing tobacco cessation program. Tob Prev Cessation. 2020;6:53. https://doi.org/10.18332/tpc/127122.

29 Heatherton TF, Kozlowski LT, Frecker RC, Fagerstrom KO. The fagerström test for nicotine dependence: a revision of the Fagerstrom tolerance questionnaire. $\mathrm{Br} J$ Addict. 1991;86(9):1119-1127. https://doi.org/10.1111/j.1360-0443.1991. tb01879.x.

30 Ebbert JO, Patten CA, Schroeder DR. The fagerström test for nicotine dependencesmokeless tobacco (FTND-ST). Addict Behav. 2006;31(9):1716-1721. https://doi. org/10.1016/j.addbeh.2005.12.015.

31 Global Adult Tobacco Survey (GATS). Indicator guidelines. Accessed https://www. who.int/tobacco/surveillance/en_tfi_gats_indicator_guidelines.pdf. Accessed January $31,2021$.

32 Bruine de Bruin W. Age differences in COVID-19 risk perceptions and mental health: evidence from a national U.S. Survey conducted in march 2020. J Gerontol B Psychol Sci Soc Sci. 2021;76(2):e24-e29. https://doi.org/10.1093/geronb/gbaa074.

33 Simons D, Shahab L, Brown J, Perski O. The association of smoking status with SARSCoV-2 infection, hospitalization and mortality from COVID-19: a living rapid evidence review with Bayesian meta-analyses (version 7). Addiction. 2021;116(6): 1319-1368. https://doi.org/10.1111/add.15276.

34 Kim S, Kim S. Analysis of the impact of health beliefs and resource factors on preventive behaviors against the COVID-19 pandemic. Int $J$ Environ Res Publ Health. 2020;17(22):8666. https://doi.org/10.3390/ijerph17228666.

35 Snell M, Harless D, Shin S, Cunningham P, Barnes A. A longitudinal assessment of nicotine dependence, mental health, and attempts to quit Smoking: evidence from waves 1-4 of the Population Assessment of Tobacco and Health (PATH) study. Addict Behav. 2021;115:106787. https://doi.org/10.1016/j.addbeh.2020.106787. 